\title{
El documental de animación: un género audiovisual digital
}

\author{
Animazio-dokumentala: ikus-entzunezko genero digitala \\ Animated Documentary: A Digital Audiovisual Genre
}

\author{
Sonia García López ${ }^{\star}$ \\ Universidad Carlos III de Madrid
}

RESUMEN: Este artículo caracteriza el documental de animación entendido como género audiovisual que se consolida a escala global con la cultura digital y comienza a implantarse en el contexto hispanohablante. Adoptando herramientas teóricas del campo de la historia, la estética y la tecnología audiovisual, plantea la vinculación del género con las especificidades de la imagen digital y se discuten cuestiones como la crisis del valor referencial de la imagen audiovisual en la cultura contemporánea y la funcionalidad del documental de animación en la representación de realidades mentales, procesos históricos y políticos de los que no existe registro audiovisual, o la documentación del trabajo artístico.

PALABRAS CLAVE: Documental; digital; creatividad; construcción de la realidad; documental animado.

ABSTRACT: This essay defines the animated documentary as an audiovisual genre that is consolidated with the digital culture in the global context, and that starts to be consolidated the Spanish speaking regions. Drawing upon theoretical tools from the film history, aesthetics, and technology, it assesses the existing bond between this genre and the specificities of the digital image, discussing topics such as the problematic status of the audiovisual image referential value in the digital culture, and the functionality of the animated documentary for the representation of mental realities, political and historical processes lacking audiovisual records, or the documenting processes of the artistic labor.

KEYWORDS: Documentary; digital; creativity; construction of reality; animated documentary.

\footnotetext{
* Correspondencia a / Corresponding author: Sonia García López. Universidad Carlos III de Madrid. Facultad de Humanidades, Comunicación y Documentación. C/ Madrid 133. 28903 Getafe (Madrid) - sogarcia@hum.uc3m.es - http://orcid.org/0000-0001-6716-0090

Cómo citar / How to cite: García López, Sonia (2019). «El documental de animación: un género audiovisual digital»; Zer, 24(46), 129-145. (https://doi.org/10.1387/zer.20396).
}

Recibido: 16 noviembre, 2018; Aceptado: 27 abril, 2019.

ISSN 1137-1102 - elSSN 1989-631X / (C) 2019 UPV/EHU

(c) (i) Esta obra está bajo una licencia 


\section{Introducción ${ }^{\star}$}

Los caminos de la animación y la no ficción parecen haber discurrido por sendas paralelas desde los primeros tiempos del cine: la animación, estrechamente ligada a las viñetas cómicas, a las Bellas Artes y, en general, a los medios de expresión artística; la no ficción, vinculada al interés por lo real, a los discursos informativos y al valor indicial de la imagen fotocinematográfica. Hasta cierto punto, ese divorcio entre la animación y el documental sigue presente cuando consideramos la literatura especializada sobre animación o la escasa presencia de esta disciplina en revistas de cine de temática general, o cuando examinamos los itinerarios curriculares de universidades y escuelas de cine y observamos que las asignaturas y técnicas de animación siguen enseñándose en el ámbito de las Bellas Artes, mientras que se encuentran prácticamente ausentes en los estudios sobre Cine y Comunicación audiovisual ${ }^{1}$. No obstante, desde que las tecnologías digitales se generalizaron como medio de expresión audiovisual a mediados de la década de 1990, el documental de animación se ha ido consolidado como género cinematográfico. Dicha consolidación puede y debe ser definida desde un punto de vista cultural e intelectual, y no únicamente desde unos parámetros textuales que, como veremos, están presentes de todos modos en los documentales que se designan como tales.

Desde este punto de vista, la consideración del documental de animación o documental animado como un nuevo género audiovisual ofrece un excelente ejemplo del argumento de la comprensión de los géneros cinematográficos como formaciones discursivas de carácter histórico que propone Rick Altman. Frente a las consideraciones más esencialistas de los géneros en las que todo argumento sobre los límites de un corpus genérico implica la oposición entre una lista excesivamente general o un canon exclusivo y excesivamente excluyente (Altman, 1984), Altman propone un modelo dinámico del género cinematográfico, que denomina semántico-sintáctico. Ese modelo pone de relieve la dimensión histórica y sujeta a constantes mutaciones de todo género cinematográfico, así como la influencia que ejercen en la definición y consolidación de un género los productores, los críticos cinematográficos, la academia y el público (Altman 1999). En consonancia con lo planteado por

\footnotetext{
* La autora desea expresar su agradecimiento a Roberto Cueto por haber compartido un conjunto de referencias audiovisuales que son objeto de análisis en el presente artículo y por la invitación a escribir el texto que dio pie a desarrollos posteriores de la investigación cuyos resultados se recogen en esta contribución.

1 Constituyen notables excepciones, en este sentido, los estudios de grado y de postgrado que ofrecen la University of Southern California (grado en Animación y Artes digitales, Espectáculos interactivos; Máster en Animación y Artes Digitales, Medios Interactivos) y el California Institute of the Arts (grado en Personajes y Animación experimental; Cursos de extensión en Animación y Residencia de verano en Animación).
} 
Altman, Bill Nichols (1997) elude las caracterizaciones esencialistas de una forma filmica históricamente huidiza como es el documental para ofrecer criterios históricos, objetivos y dinámicos en su caracterización, en la que el punto de vista de la comunidad de realizadores que se reconocen como documentalistas, la inserción en circuitos institucionales específicos y unas determinadas condiciones de recepción adquieren tanto peso como unas determinadas características textuales.

Al defender la identidad del documental de animación como un género audiovisual que se consolida con la cultura digital, este artículo pretende poner de manifiesto que su implantación responde a problemáticas históricas y tecnológicas planteadas de manera específica por la naturaleza de la imagen digital. Desde ese punto de vista, si bien la exploración de las intersecciones históricas entre animación y documental es fructífera para pensar en los problemas teóricos y estéticos que plantea este género, la pretensión no es trazar una genealogía del mismo que nos lleve a pensarlo desde criterios esencialistas (algo, por lo demás, inasumible dentro de los límites de un artículo). Más bien, se trata de evaluar el modo en que su implantación y aceptación por parte de una comunidad de creadoras y creadores, su inserción en circuitos especializados, sus características textuales y el reconocimiento por parte de la crítica, el público y la academia nos hablan de la aparición de nuevas formas de articulación de lo real en la era digital ${ }^{2}$. Teniendo en cuenta esos aspectos, Annabelle Honess Roe proporciona una definición del documental de animación entendido como:

un trabajo audiovisual (producido digitalmente, filmado o directamente manipulando el soporte en celuloide) que: $1 /$ ha sido grabado o creado frame a frame; $2 /$ trata sobre $e l$ mundo más que sobre un mundo imaginado en su totalidad por la o el creador; $3 /$ ha sido presentado como documental por sus productores y/ o recibido por su público, por festivales o en la consideración crítica como documental. (Honess Roe, 2013: 4) ${ }^{3}$

Para Honess Roe, este último criterio es significativo porque ayuda a diferenciar películas que pueden ser consideradas similares desde un punto de vista estético, pero que estarían motivadas por intenciones diversas de sus respectivos productores o recibidas de otra forma por el público. Además, esta caracterización ayuda a delimitar el campo: las películas publicitarias, científicas, educativas o institucionales, en las que la animación se utiliza con frecuencia, están más allá de lo que la autora con-

\footnotetext{
2 Desde este punto de vista, la inclusión de la categoría «documental de animación» o «documental animado" para el Thesaurus de la revista Zer que propone este artículo puede ser considerada sintomática del carácter incipiente que tiene la consideración de esta forma audiovisual, a pesar de que en el momento de la escritura de este texto ya existen numerosas expresiones audiovisuales, críticas y académicas que apuntan a su consolidación en la cultura audiovisual digital.

${ }^{3}$ La traducción es mía en todas las citas procedentes de textos escritos en otros idiomas.
} 
sidera documentales de animación porque no responden a una intención documental ni son recibidas como tales (Honess Roe, 2013: 4).

En última instancia, la emergencia, relativamente reciente, de este género en el ámbito hispanohablante, redunda en esa comprensión histórica de las formas audiovisuales, cuya popularización, más allá de criterios estéticos, industriales o comerciales, tiende a ser geográficamente desigual a pesar de su carácter global. La consideración del documental de animación en España y América Latina (necesariamente introductoria en un texto de estas características) apunta, en este sentido, a inscribir algunas de estas producciones en un marco de comprensión global.

Confirman, pues, y legitiman esa consolidación del documental de animación la proliferación de producciones que se reivindican como tales y la presentación de programas cinematográficos bajo esta categoría en festivales y cinematecas. Desde este punto de vista, el estreno en el Festival de Cannes de la película israelí Vals con Bashir (Vals im Bashir, Ari Folman, 2008) — que emplea la técnica de animación con cut-out digital para relatar la experiencia del director como veterano de la guerra del Líbano de 1982 - , se erige como piedra de toque en la consolidación de este género. Cabe citar, en este mismo sentido, las iniciativas pioneras del International Documentary Film Festival Amsterdam (IDFA) (Driessen, 2007) y el Festival y Mercado International de Cine Documental Miradas Doc de Santa Cruz de Tenerife MiradasDoc, 2008), que presentaron sendos programas audiovisuales consagrados al documental de animación en 2007 y 2008 respectivamente. Además, y muy especialmente en el contexto que nos interesa, podemos hablar de una serie de publicaciones críticas y académicas que desde hace varios años reflexionan sobre las relaciones entre animación y documental (Lorenzo Hernández, 2010; Moore, 2011) o directamente se centran en el documental de animación como forma específica (Català 2010; Kriger, 2012; Honess Roe, 2013). La categoría de 'documental de animación' goza, pues, de una amplia aceptación, tanto en el ámbito de la producción como en los de la crítica y la reflexión teórica que se empieza a ver reflejada en el contexto hispanohablante, en el que recientemente han aparecido una serie de trabajos que permiten explorar intersecciones históricas y teóricas específicas entre discursos emparentados con el documental, como la historia y las escrituras del yo, con el cómic o la novela gráfica (Lluch-Prats, Martínez Rubio y Souto, 2016; Galán Fajardo y Rueda Laffond, 2016). Más puntuales son las reflexiones que atañen directamente al cine y el audiovisual, campos en los que el documental de animación sigue siendo una categoría de análisis poco trabajada, aunque poco a poco van apareciendo producciones, ensayos críticos y muestras cinematográficas que van cubriendo ese campo ${ }^{4}$.

\footnotetext{
${ }^{4}$ Véase, por ejemplo, las fugaces referencias al uso de la animación en el documental didáctico y científico español en De la Rosa (1996) o la reflexión sobre el empleo de la animación en los documentales agropecuarios del Marqués de Villa-Alcázar en los primeros años de la dictadura franquista en Poyato Sánchez (2016).
} 
Annabelle Honess Roe (2013) ha publicado el trabajo más completo, hasta el momento de la escritura de este artículo, sobre el documental de animación. En su libro Animated Documentary, la autora no solo realiza un acercamiento teórico a esta forma audiovisual característica de la cultura digital, sino que analiza un voluminoso corpus de películas. No obstante lo que a nuestro modo de ver resulta más interesante, dada la amplitud de su corpus de trabajo, es que Honess Roe evita en su acercamiento la perspectiva teleológica, que recorrería de manera lineal la historia compartida de la animación y el documental desde las primeras intersecciones (donde The Sinking of the Lusitania, realizada por Winsor McCay en 1918 emerge como película fundacional) hasta los más recientes ejemplos. Honess Roe se decanta, más bien, por el estudio de las discontinuidades, prefiriendo llamar la atención sobre «algunas tendencias significativas en las primeras intersecciones entre animación y documental, así como el giro hacia el desarrollo del documental de animación como una forma de pleno derecho» (p. 5). En otras palabras, más que trazar una genealogía del documental de animación, la autora opta por proponer una «arqueología» en el sentido foucaultiano, buscando filiaciones históricas, más que orígenes (cfr. p. 5) y trabajando a partir de la afirmación de Thomas Elsaesser de que «solo la presunción de discontinuidad y la sinécdoque del fragmento pueden aspirar a proporcionar acceso al pasado»(p. 6).

Al igual que en el ámbito más global, en el entorno hispanohablante encontramos intersecciones tempranas entre documental y animación en el terreno del cine educativo y científico, la vanguardia cinematográfica y el cine experimental que nos permitirían llevar a cabo una labor similar la que propone Honess Roe, pero circunscrita a unas coordenadas geográficas en las que el documental de animación sigue siendo, como hemos apuntado, incipiente. No obstante, nos centraremos en este artículo en la etapa contemporánea, en la que, poco a poco, esta forma audiovisual se va consolidando, también en España y en América Latina, como género. Debido al alto coste económico y temporal de las películas de animación, el documental de animación se ha desarrollado fundamentalmente bajo la forma del cortometraje, por lo que es imprescindible no perder de vista este formato poco atendido por los estudios fílmicos a la hora de reflexionar sobre el documental de animación. No obstante, la aparición de largometrajes documentales de animación en España y en América Latina puede ser leída como un indicio de su consolidación y aceptación como categoría específica. Es el caso de la producción argentina Eva de la Argentina (María Seoane, 2011) o la española 30 años de oscuridad (Manuel H. Martín, 2011), una novela gráfica documental, según sus creadores, que combina animación, imagen de archivo y entrevistas a testigos y voces autorizadas. Pero, antes de profundizar en cuestiones más específicas, parece necesario exponer algunos presupuestos sobre el documental de animación entendido como categoría de análisis y como género cinematográfico. 


\section{Animación y documental: dos tradiciones enfrentadas}

Resulta, de entrada, muy notable, el hecho de que en el documental de animación se dan cita dos finalidades aparentemente enfrentadas: la vocación referencial que tradicionalmente preside el cine documental (afianzada por la naturaleza mecánica de los medios de registro de lo real) y el carácter expresivo que es inherente al cine de animación (en el que la mano del artista dificilmente se sustrae al producto final). Al margen de su consolidación en el ámbito comercial y artístico, el cine y la fotografia se erigieron durante décadas como los grandes aliados de los discursos sobre la identidad (en las fotografias de registro policial y los pasaportes), la verdad (funcionando como pruebas en procesos judiciales) y la representación de la realidad (en el noticiario, el documental y el reportaje televisivo) ${ }^{5}$. En cierto modo, la imagen documental, ya se tratase de fotografia o de cine, terminó adoptando la condición del lenguaje clásico, al que Roland Barthes (1997) atribuye una economía relacional en la que la función comunicativa prima sobre la expresiva, es decir, la relación de transitividad entre el objeto representado y su expresión prevalece sobre el carácter construido, artificial, del lenguaje que articula la representación. Se crea, así, la ilusión de transparencia entre la realidad y el lenguaje que la representa.

Del mismo modo, la naturaleza codificada del discurso cinematográfico, sobre la que, al menos desde la década de 1920, llamaron la atención cineastas como Dziga Vertov, Elizaveta Svilova y Mikhail Kaufman con su Kino Pravda (1922-1925) o, algo después, Jean Vigo (1930), quedó ensombrecida históricamente por el valor documental asociado a la capacidad de la imagen fotoquímica para reproducir la realidad por medios exclusivamente mecánicos, a diferencia de la pintura o el dibujo, a los que la intervención de la mano humana les es consustancial. Durante la década de 1930, en que Bill Nichols sitúa el «momento histórico del documental» (2001: 1), esta forma filmica se institucionaliza en occidente como un tipo de cine cuya finalidad última no es tanto la expresión de lo real a través de la subjetividad del cineasta como la representación de la realidad con fines de persuasión social. Partiendo de otros presupuestos, durante las décadas de 1940 y 1950, André Bazin (1966) elaboró a través de diversos escritos la que acabaría consolidándose como una de las principales teorías del realismo cinematográfico, proporcionando una base intelectual a la consideración de la imagen fotoquímica como huella de lo real.

Sin embargo, con el cambio de siglo, la tecnología digital vino a poner en cuestión ese vínculo íntimo, casi consanguíneo del celuloide con lo real: el sistema de codificación y descodificación binaria, que descompone los atributos de la imagen en

\footnotetext{
5 Sobre la utilización de la fotografía como sistema de autentificación policial y legal véase Tagg (2005); para la imagen como representación de la realidad véanse los clásicos estudios de Nichols (1997) y Chanan (2007).
} 
unidades de información intercambiables, igualaba democráticamente las señales de luz y de color procedentes de un registro real con las producidas mediante un software informático, haciendo virtualmente imposible distinguir una imagen tomada de la realidad de una fabricada por ordenador ${ }^{6}$. Más allá de las incontables implicaciones del nuevo y problemático estatuto de la imagen con respecto a la realidad — descritas ampliamente por teóricos de la postmodernidad como Jean Baudrillard (1993; 1997) y Paul Virilio (1988), entre otros - que llegaron con las nuevas tecnologías, la emergencia de la cultura visual digital resulta fundamental para comprender el intenso diálogo a escala global que actualmente protagonizan el cine de animación y el documental.

La posibilidad de producir imágenes hiperrealistas generadas por ordenador en el cine de animación contemporáneo ha llevado más lejos la tradición mimética que atraviesa la historia de las artes plásticas en occidente, introduciendo un grado de realismo nunca visto en entornos narrativos conscientemente alejados del realismo o la verosimilitud. En esas películas la sustitución del cuerpo del actor o la actriz por uno creado artificialmente, se convierte en una fantasía (o en un fantasma) que mayor fascinación despierta cuanto más dificil resulta distinguir entre el original y la copia. No es otro el tema de la película El congreso (The Congress, 2014), segundo largometraje del creador de Vals con Bashir, Ari Folman. En esta adaptación de la novela de Stanislav Lem El congreso de futurología (Kongres futurologiczny, 1971), Folman emplea una técnica mixta en la que se combina acción real interpretada por actrices y actores con animación para relatar la historia de Robin Wright, una actriz (encarnada por la intérprete homónima) que recibe la oferta de explotar su cuerpo digitalmente para generar películas protagonizadas por ella usando tan sólo personajes generados por ordenador. Por otro lado, filmes como Avatar (Avatar, James Cameron, 2009) o Una mirada a la oscuridad (A Scanner Darkly, Richard Linklater, 2006), en la que los personajes son el resultado de imágenes de síntesis que combinan la filmación de la acción real con el dibujo a través de la rotoscopia ${ }^{7}$, funcionan como ejemplo de esa convivencia entre hiperrealismo e hiperfantasía, que Andrew Darley (2003) considera como rasgo definitorio de la cultura visual digital.

No obstante, mientras que el perfeccionamiento técnico que permite la sustitución de cuerpos y objetos reales por imágenes de síntesis se encuentra en la base de una cultura del entretenimiento que se sustenta en la simulación y el hiperrealismo, la vía por la cual la animación ha entrado en el documental con películas como Vals con Bashir, Chicago 10 (Chicago 10, Brett Morgen, 2007) o Campo 14. Zona de control total (Camp 14. Total control zone, Marc Wiese, 2012) responde a circunstancias muy distin-

${ }^{6}$ A este respecto, pueden consultarse los trabajos de Quintana (2003:271-280; 2011).

7 En este caso, se trata de una evolución digital, a través del programa Rotoshop, desarrollado por Bob Sabiston para la película de Linklater, de la técnica patentada por el pionero de la animación Max Fleischer en 1915. Véase Kriger (2012:18). 
tas. No podía ser de otro modo tratándose de dos ámbitos, el de la animación y el del documental, cuya relación con lo real es aparentemente antagónica: mientras que la primera se ha consolidado como territorio de la fantasía y del entretenimiento, el segundo se asocia con la representación de la realidad y con los discursos de sobriedad.

\section{Documental de animación: dos tradiciones reconciliadas}

Al aparente antagonismo entre animación y documental subyace, en el documental de animación, la necesidad de encontrar otras vías de legitimación de la verdad documental en un momento en que el carácter probatorio de la imagen fotocinematográfica ha caído en descrédito ante la incertidumbre creciente con que nos enfrentamos a la autenticidad de las imágenes ${ }^{8}$. Como veremos, esta no es la única motivación, pues el cuestionamiento radical del valor indicial de la imagen analógica ha abierto también vías para la representación de acontecimientos sociales o históricos de los que no existen registros audiovisuales o aspectos de lo real que no necesariamente pasan por lo visible, como son los estados mentales vinculados al sueño, la memoria, la locura o los procesos creativos.

Desde este punto de vista, no parece casual que las técnicas de animación utilizadas en estos documentales eludan con frecuencia el hiperrealismo y enfaticen su carácter de representación, en franca oposición al verismo del material de archivo: el cut-out digital en Vals con Bashir, la estética de cómic de Chicago 10, la navegación por viñetas estáticas que encontramos en 30 años de oscuridad, la animación ocasional de fotografias reales en Crulic, camino al más allá (Crulic. Drumul spre dincolo, Anca Damian, 2011), que también encontramos en el cortometraje experimental de Isabel Herguera Spain Loves You (1988), o el diorama filmado, que Albertina Carri utilizó de forma pionera en Los Rubios $(2003)^{9}$ y que Rithy Panh emplea de manera más sistemática en La imagen perdida (L’image manquante, 2013), son algunas de las técnicas que se ponen en juego.

Evidentemente, el presupuesto con que suelen contar este tipo de películas, bastante más limitado que el de las grandes producciones de animación, condiciona desde el principio el recurso a las técnicas más humildes. Pero, al margen de eventuales limitaciones presupuestarias, la reflexión sobre la técnica sostenida por realizadores y equipo de animación en entrevistas (Moore, 2011; Honess Roe, 2012; Jriger, 2012), e incluso en los propios filmes, sugieren que los procedimientos escogidos responden a necesidades específicas y resultan clave para la función de epistefilia o el placer del co-

\footnotetext{
8 Véase, por ejemplo, Ramonet (1998), Català (2011) y Fontcuberta (2016).

9 En este documental la directora representa escenas de la vida familiar con sus padres, desaparecidos durante la dictadura argentina, a través de dioramas filmados en los que se utilizan figuritas de Playmobil.
} 
nocimiento que caracteriza a la recepción del documental. Concretamente, es clave el pacto de lectura espectatorial en virtud del cual se acepta la naturaleza mecánica, artificial de los recursos de animación utilizados, al mismo tiempo que las expectativas se orientan a la recepción de un discurso sobre el mundo histórico o de la realidad subjetiva. Judith Kriger pone de manifiesto esa relación dual en el documental de animación cuando afirma al respecto de Vals con Bashir que «la historia es muy personal e intensa, [parece] dibujada a mano, puede percibirse la imperfección de las líneas. De modo que puede percibirse la presencia humana tras la cámara» (Kriger 2012: 21). Por su parte, Chris Landreth expresaba el sentido de su renuncia al hiperrealismo característico de la animación digital comercial en sus notas para la película Ryan (Chris Landreth, 2004), dedicada al animador canadiense Ryan Larkin:

Lo que más me interesa no es alcanzar una estética fotorrealista a través de imágenes generadas por ordenador, sino cooptar los elementos del fotorrealismo con fines distintos, exponer el realismo de los aspectos complejos, caóticos, desordenados, en ocasiones mundanos y siempre conflictivos de eso que llamamos condición humana. Me refiero a ello como «psicorrealismo». (Moore, 2011)

La justificación del valor documental de unas técnicas tradicionalmente asociadas a otras formas audiovisuales se desprende, asimismo, de la invocación, en Vals con Bashir, de los procesos creativos que intervienen en el acto de recordar, cuestionando la extendida asimilación de los recuerdos a la fotografia, o la reflexión sobre la ambivalencia de la imagen documental que Rithy Panh introduce en numerosas escenas de La imagen perdida.

Podemos convenir, pues, que la desmitificación del vínculo de la imagen analógica con lo real ha terminado por dar cabida a unos usos de las técnicas de animación en el documental que se caracterizan por una dimensión creativa (y, en ocasiones, incluso dialéctica respecto a la imagen de archivo) que antes resultaba impensable más allá de la película científica o de carácter didáctico, géneros en los que la animación funciona como mera «ilustración» de lo expuesto por la voz omnisciente del narrador. Como afirma Josep M. Català (2010: 35) el documental se definió tradicionalmente:

por su grado de analogía visual con la realidad, mientras que ahora valoramos su capacidad hermenéutica para profundizar en una realidad cuya esencia no culmina necesariamente en lo visible. Es por eso que ahora podemos seguir hablando de un espíritu documentalista al referirnos a filmes de animación (...).

Por lo demás, las líneas temáticas dominantes en los documentales de animación contemporáneos nos informan de que, lejos de la ironía postmoderna o el relativismo del «todo vale» que cabría deducir de la crisis de los códigos de representación tradicionales del documental, el uso de la animación responde a necesidades específi- 
cas que, según los casos, tiene que ver con criterios temáticos y estéticos y/o éticos e ideológicos. Desde este punto de vista, encontramos tres grandes ejes en el documental de animación: por una parte, las cuestiones relacionadas con la salud, y más concretamente, con la salud mental y la psicología (patologías y trastornos mentales, mundo onírico, memoria), que vemos ejemplificado en el uso de la animación en cortometrajes como "A is for Autism» (Tim Webb, 1992) y El viaje de María (Miguel Gallardo, 2010) o en los largometrajes Vals con Bashir o María y yo (Félix Fernández de Castro, 2010); por otra, los derechos humanos (situaciones de represión y supresión de los individuos en regímenes dictatoriales, etc.), presente en documentales animados como Crulic, Camp 14 o 30 años de oscuridad; en tercer lugar, los procesos creativos (sobre todo relativos a la obra de artistas que trabajan con la pintura, el dibujo o la propia animación) que encontramos en trabajos como Ryan, Cutie and the Boxer (Zachary Heinzerling, 2013), On Vampyres and Other Symptoms (Celia Novis, 2011) o María y yo. La articulación de estas tres líneas temáticas del documental de animación no es infrecuente, y existen numerosos trabajos que abordan, por ejemplo, la representación de estados o realidades mentales junto con la necesidad de encontrar mecanismos para dar cuenta de situaciones, presentes o pasadas, que han dejado una huella invisible en los cuerpos de los sujetos pero que, por su carácter inmaterial o por su anacronismo, no pueden ser representados con las herramientas habituales del documental.

En sintonía con la línea colaborativa que parece haberse abierto entre el documental y los procesos creativos asociados a la ilustración, la pintura y el dibujo, en la que aquel se postula como una de las herramientas de popularización y legitimación de estos, aparecen una serie de documentales que abordan la biografia de creadores: es el caso de los citados Ryan, Cutie and the Boxer, protagonizada por los artistas Ushio y Noriko Shinohara, o el documental español On Vampyres and other Symptoms, consagrado a revitalizar la figura del dibujante y director de fantaterror José Ramón Larraz. Todos ellos incluyen la animación de obras de los personajes retratados como elemento fundamental para la representación de su universo creador, tanto desde un punto de vista material, mediante la filmación de sus obras, como conceptual, animándolas con sus fantasías, sus sueños o sus maneras de entender la vida y el arte. Concretamente, On Vampyres and Other Symptoms aborda la figura y la obra de Larraz a través «sus mismos elementos, recursos y estética» (Novis 2011), de modo que la fantasía, el misterio y la fascinación por lo desconocido que impregnan la persona y las películas de Larraz son también las que dan forma a este documental. Son el sonido, ya anacrónico, del proyector en la sala de cine, la música de Antonio Meliveo, repleta de disonancias y notas sostenidas, las voces del guion leídas por Marianne Morris y Anulka, vampiras de Larraz, y las ilustraciones de Cesc Pujol, acompañadas por unos efectos sonoros que parecen llegar directamente desde el pasado, los que nos sumergen en el estilo y la plástica de los filmes del director barcelonés. El resto lo obran los fragmentos extraídos de sus propias películas, que nos adentran en los frondosos bosques ingleses, en los que la bruma todo lo envuelve, y en apartadas casas solariegas en las que acechan todos los peligros imaginables, con sus placeres. 
Desde esa misma perspectiva que emparenta al documental con los aspectos biográficos de la pintura, la animación y la ilustración, parece más que justificado el recurso a la animación que observamos en toda una serie de documentales que se nutren de la revitalización (y legitimación por parte de la alta cultura) que ha vivido el cómic en las últimas décadas. Persépolis, la obra autobiográfica de Marjane Satrapi, que contó con Vincent Paronnaud para dirigir la versión cinematográfica (Persepolis, 2007), es pionera en este campo. Por su parte, constituye una referencia fundamental en el contexto español la citada María y yo, adaptación del cómic homónimo (2007) en el que el dibujante Miguel Gallardo relata las vacaciones con su hija autista en un resort canario. En ambos casos el ingrediente autobiográfico que preside las obras adaptadas se refuerza, en las versiones cinematográficas, con la participación de sus autores como guionistas, como es el caso de Satrapi, o como protagonistas, caso de Miguel Gallardo ${ }^{10}$. Este último, en concreto, ha incursionado en el campo de la dirección con la creación de dos cortometrajes continuadores de la estética y la temática de María y yo: «El viaje de María» (2010) y «Academia de especialistas» (2012), producidos ambos por la Fundación Orange, que ya colaborara en el largometraje de Félix Fernández de Castro. Si en el caso de la obra de Satrapi el recurso a la animación es total en la adaptación cinematográfica y, en este sentido, consistente con la novela gráfica firmada por la autora de origen iraní, en el caso de María y yo la acción real (las escenas en las que vemos a María y Miguel Gallardo) se combina con la animación en momentos puntuales y, lo que es más importante, formalmente justificados, puesto que se recurre a esta técnica para expresar aspectos de la realidad mental de María.

Por lo demás, en María y yo la reivindicación del dibujo y, más concretamente, del cuaderno de apuntes como expresión de la subjetividad, invierte el lugar subalterno que la técnica manual siempre ocupó respecto a la fotografía a la hora de dar cuenta de la experiencia vital. Miguel Gallardo pone en juego el valor documental del «apunte» al contar la forma en que vivió como dibujante el diagnóstico de autismo de su hija María: «otros padres tomaban fotos. Yo dibujaba. Deformación profesional, supongo. El cuaderno se cerró cuando empezaron las primeras pruebas con María». Y más tarde añade: «Soy un dibujante de técnica, pero cuando comencé a dibujar con María comencé a hacerlo del natural, usando la memoria. Tomaba notas y apuntes en cualquier lugar y me acostumbré al esbozo». Esta reivindicación del valor documental del apunte que Gallardo hace en María y yo no quedó limitada a los confines de la película, sino que desarrolló en un trabajo posterior de Gallardo como dibujante: el cuaderno digital Los viajes de María (2012), compuesto por 40 páginas extraídas de sus cuadernos de viaje, con respecto al que Gallardo expresó su voluntad de «hacer algo en digital, directo de la libreta al PDF, sin ninguna reelaboración» (Gosálvez, 2012).

10 Evidentemente, no se trata de casos aislados. Véase, por ejemplo, Lorenzo Hernández (2010). 
En realidad, el valor documental del dibujo precede a la fotografia y, en cierto modo, sigue existiendo en las prácticas institucionales, por ejemplo en los procesos judiciales. En este sentido, la artista argentina Azul Blaseotto, que durante cinco años realizó un trabajo de campo en los Tribunales Federales de Comodoro Py de la Ciudad de Buenos Aires, ha conceptualizado lo que ella misma denomina «R/E: Registro exacto desde los juicios por crímenes de lesa humanidad» (2014). Se trata de dibujos que:

se construyen, como la memoria, por tramos de experiencia. Las líneas no apuntan a representar el pasado sino a tomarle el pulso al presente, a presentarse en imagen y palabra dentro del rito judicial de establecer la verdad sobre lo ocurrido. Es en este sentido que mi práctica es dibujo documental.

Reconociéndose en los antecedentes documentales del dibujo, Blaseotto - que comenzó colaborando con H.I.J.O.S Capital cuando desde los juzgados se prohibió fotografiar o filmar las audiencias - manifiesta haber retomado la misma tarea que encaraban los reporteros gráficos con anterioridad a la invención de la fotografia, y como tales acompañaron a las crónicas de los juicios aparecidas en diarios y portales web argentinos como Página 12 o Infojus. Junto a otros artistas, y en colaboración con distintas asociaciones de lucha en el campo de derechos humanos, Blaseotto también participó en el proyecto documental Historietas X la Identidad de Abuelas de Plaza de Mayo (2015) con el fin de ayudar a difundir sus campañas.

Más allá del valor documental último que, en filmes como María y yo, On Vampyres and Other Symptoms, Cuttie and the Boxer o Ryan, se desprende del hecho mismo de poner ante la cámara el resultado del trabajo de los creadores retratados, se pone en ellos de manifiesto el valor del dibujo y la pintura en tanto que herramientas de expresión de realidades subjetivas como la creatividad, el autismo o la experiencia y el recuerdo personal o familiar. Desde este punto de vista, la tentativa de incluir animaciones derivadas de los cuadernos de apuntes de los artistas en documentales, entronca con una de las tendencias dominantes en el documental de finales del siglo xx y principios del xxI: la que desliza su objeto de interés de la representación del mundo histórico o social, considerada por el documental clásico, a la representación de la realidad sensorial, psicológica y subjetiva que se ha manifestado bajo la forma del documental autobiográfico, el film ensayo o la etnografia experimental en las últimas dos décadas ${ }^{11}$. Precisamente en ese radio de acción se sitúan los documentales de animación propiamente dichos, que emplean la animación no como complemento, sino como recurso fundamental. Trascendiendo la aproximación estética o temática de los ejemplos expuestos previamente, estos documentales plantean esa opción como una elección ética e ideológica, es decir, como una toma de posición.

11 Sobre estas cuestiones pueden consultarse los trabajos de Nichols (1994), Russell (1999) y Renov (2004). 
Vals con Bashir es, desde este punto de vista, un filme pionero en el que, tanto el uso de animación como la inserción de unos fragmentos de archivo audiovisual al final del filme, responden a una deliberada posición del realizador con respecto a la verdad documental (cómo contarla) y al uso de material de archivo. A este respecto, afirma el director de animación en Vals con Bashir, Yoni Goodman:

La animación posee una especie de cualidad «distanciadora», lleva al público más lejos. (...) Intencionalmente jugamos con ello — hacer que el público viera todas estas cosas horribles que ocurrieron durante la guerra. (...) La gente vio más, creo, porque lo hicimos desde este punto de vista. (...) Sí, creo que cuando ves algo y tu mente te dice: vale, no es real, tiendes a abrirte. Y luego piensas, espera un minuto, esto es real. Lo que estoy viendo es algo perturbador... pero ya se ha producido la inmersión. Puedes abrirte más al tema. (Kriger, 2012: 22)

En la película de Ari Folman, pero también en La imagen perdida, se plantea el recurso a la animación para dar cuenta de una realidad de la que no existen registros stricto sensu (la del trauma y la de la memoria) o para recusar un uso de la imagen de archivo que desvirtúa la experiencia, ya sea a través del vaciado de sentido que propicia la sobreexposición mediática o a través de la manipulación propagandística propia de los regímenes dictatoriales. En todos esos casos, la subjetividad del cineasta y / o del protagonista del documental de cuyo relato se hace cargo el realizador se oponen a la voz omnisciente del documental o el reportaje tradicional estableciendo (o reactivando) otros mecanismos de legitimación, como el compromiso ético o el valor testimonial.

La película 30 años de oscuridad da un paso más en la representación de una realidad de la que no existen registros filmados, en este caso para contar una historia que el director no ha vivido en primera persona, sino que concierne a otros individuos. En 30 años de oscuridad la dimensión no visible de la represión de Estado es objeto de tematización desde el propio título, que alude al mismo tiempo a la oscuridad en la que vivieron algunos combatientes antifranquistas tras la guerra civil y a invisibilidad de discursos que rescaten su memoria ${ }^{12}$. Según las notas de producción de la película:

la historia de los llamados «topos» españoles tiene un paralelismo con otros conocidos «encierros» provocados por la represión. La adolescente Anna Frank estuvo escondida junto a su familia durante dos años y medio en Amsterdam; el soldado Soichi Yokoi permaneció 28 años en una caverna sin

12 En este sentido, la película dialoga con la película la rumana Crulic, estrenada ese mismo año, que cuenta la historia de un personaje ya fallecido, y con la alemana Camp 14. Zona de control total, estrenada un año después, que aborda la realidad de los campos de reeducación norcoreanos a partir de entrevistas y de recreaciones animadas. 
saber que la II Guerra Mundial ya había acabado; el activista político Nelson Mandela permaneció en prisión durante 27 años, víctima del apartheid; la líder opositora birmana Aung San Sun Kyi fue liberada a finales de 2010 tras pasar 15 años de arresto domiciliario. (...) 30 años de oscuridad es, ante todo, una historia de supervivencia. Y en este sentido plantea una mirada universal hacia una problemática local.

Pese a reivindicar desde un primer momento los valores universales que plantea el documental, 30 años de oscuridad se centra en la historia de un individuo concreto cuya existencia está documentada: se trata de Manuel Cortés, antiguo alcalde de la localidad malagueña de Mijas que tras la guerra civil no tuvo ocasión de escapar de España y decidió, con la ayuda de su esposa, esconderse en un hueco creado a tal efecto entre las paredes de su casa. Al igual que otros tantos «topos», allí permaneció durante 30 años, hasta 1969. Sin duda alguna, lo primero que llama la atención en 30 años de oscuridad, es que la caracterización de Manuel Cortés y de su familia no se corresponde con la de los personajes reales, sino que remite a figuras bien conocidas de la cinematografía española que prestan su voz y su imagen a los protagonistas de la historia: Juan Diego encarna a Manuel, mientras que su esposa Juliana Moreno es interpretada por Ana Fernández. La utilización de estos dos actores, con una trayectoria muy marcada en el cine realista (Los santos inocentes, Mario Camus, 1984) y de corte social (Solas, Benito Zambrano, 1999), constituye un marcador de calidad y prestigio para la película. Ciertamente, la presencia de figuras reconocidas y reconocibles por el espectador no deja de resultar chocante cuando se trata de encarnar a personas reales, y en cierto modo emparenta a este documental con subgéneros como el docudrama. Sin embargo, las «personas cinematográficas» de Juan Diego y Ana Fernández contribuyen a otorgar proyección y credibilidad extracinematográfica al proyecto, sacando la historia del plano ficcional y proyectándola sobre un discurso reivindicativo. En última instancia, la adopción del trabajo actoral para encarnar a Manuel Cortés y a Juliana Moreno responde, como en tantos otros documentales de animación («novela gráfica documental», lo denominan sus creadores), a una necesidad determinada por las circunstancias que la película se propone denunciar: Juliana destruyó todas las fotografias de Manuel por miedo a que lo descubrieran. La ausencia de registros de los cuerpos de Juliana y Manuel se constituye, desde el vacío del soporte fotográfico o filmado, en evidencia de la represión, y al mismo tiempo legitima el recurso a elementos propios de la ficción como los actores o la animación.

Tanto el recurso a la animación como el empleo de actores profesionales, pone en juego una dualidad en virtud de la cual el público puede establecer una distancia respecto al dispositivo e identificarse emocionalmente con la historia que se cuenta. La legitimidad de la relación con lo real que establece esta película se desplaza, por tanto, como en el citado ejemplo de Vals con Bashir, del verismo o de los testimonios a la toma de posición del equipo técnico y artístico, al hecho de que, como apuntara Judith Kriger respecto al filme israelí, "puede percibirse la presencia humana tras la cámara». 


\section{Conclusión}

A la luz de los trabajos considerados en este artículo, parece evidente que documental y animación, esas dos tradiciones históricamente enfrentadas, no solo se reconcilian en el presente, sino que constituyen la base de un nuevo género audiovisual, el documental de animación, que se erige como soporte de nuevas formas de expresión y discursos sobre lo real. Películas de muy diversa temática y procedencia geográfica como pueden ser Vals con Bashir, Chicago 10 o 30 años de oscuridad responden por igual a las premisas establecidas por Annabelle Honess Roe para el documental de animación al estar creadas (total o parcialmente) plano a plano, referirse al mundo real y estar conceptualizadas por sus creadores, sus espacios de recepción y su público como documentales.

Lejos de constituir una tendencia genérica que responda a fines exclusivamente comerciales o estéticos, la elección de las diversas técnicas de animación en los documentales estudiados responde a necesidades específicas que surgen, por un lado, de la problemática de la representación de lo real cuando no existen registros audiovisuales que permiten documentar determinadas situaciones o estados de conciencia; por otro, del cuestionamiento del intrínseco valor de verdad tradicionalmente asignado a la imagen fotocinematográfica en virtud del atributo indicial de los soportes analógicos. Si este último aspecto es consustancial a la emergencia de la imagen digital, independientemente del género o las tendencias estéticas, aquel que atañe a la búsqueda de alternativas al registro de lo real para la representación de determinados aspectos de la realidad es exclusiva del documental de animación en su apuesta por una nueva forma estética pero, sobre todo, ética.

Pese a resultar todavía incipiente, en el momento de escritura de este artículo, la producción de documentales de animación en el contexto hispanohablante, trabajos como María y yo, On Vampyres and Other Symptoms o 30 años de oscuridad plantean interesantes concomitancias con las expresiones del género en el contexto internacional. Nos encontramos, pues, ante una nueva vía para la creación y la reflexión audiovisual cuyo futuro parece prometedor.

\section{Referencias bibliográficas}

Altman, R. (1984). A semantic/syntactic approach to film genre. Cinema Journal, 6-18. - (1999). Film/genre. London: British Film Institute.

Barthes, R. (1973). El grado cero de la escritura. México: Siglo xxi Editores.

Baudrillard, J. (1993). Cultura y simulacro. Barcelona: Kairós.

- (1997). El crimen perfecto. Barcelona: Anagrama.

Bazin, A. (1966). ¿Qué es el cine? Madrid: Rialp. 
Catalá, J. M. (2010). Panoramas desde el puente: Nuevas vías del documental. Doc. Documentalismo en el siglo XXI, 33-52.

- (2011). Reflujos de lo visible. La expansión post-fotográfica del documental. AdComunica, (2), 43-62.

Chanan, M. (2008). The politics of documentary. Londres: British Film Institute.

Darley, A. (2002). Cultura visual digital: espectáculo y nuevos géneros en los medios de comunicación. Barcelona: Paidós.

De la Rosa, E. (1996). El cortometraje de animación. En Medina, P., González, L. M., \& Velázquez, J. M., Historia del cortometraje español. Festival de Cine de Alcalá de Henares, 387-446.

Driessen, K. (2007). Animated documentaries. IDFA.nl, https://www.idfa.nl/en/article/65671/ animatiedocumentaires

Fontcuberta, J. (2016). La furia de las imágenes: Notas sobre la postfotografía. Galaxia Gutenberg.

Galán Fajardo, E., y Rueda Laffond, J. C. (2016). Those wars are also my war: An approach to practices of postmemory in the contemporary Spanish comic. Catalan Journal of Communication \& Cultural Studies, 8(1), 63-77.

Gosálvez, P. (2012). «Los viajes de María, relatos de vacaciones con un hijo autista». Blog Turistario, El País, 6 de enero https://blogs.elpais.com/turistario/2012/01/los-viajes-demar\%C3\%ADa-y-miguel-gallardo.html

Honess Roe, A. (2012). Uncanny indexes: Rotoshopped interviews as documentary. Animation, 7(1), 25-37.

- (2013). Animated documentary. Londres: Palgrave Macmillan.

Kriger, J. (2012). Animated Realism: A Behind The Scenes Look at the Animation Tools and Techniques of Award Winning Films. Oxford: Elsevier / Focal Press.

Lluch-Prats, J., Rubio, J. M., y Souto, L. (2016). Propuestas entre la imagen y la palabra: el cómic $y$ sus contornos. Las batallas del cómic, 6 .

Lorenzo Hernández, M. (2010). A film of one's own: the animated self-portraits of young contemporary female animators. Animation, 5(1), 73-90.

MiradasDoc (2008). Documental y animación. Una propuesta sobre lo real. Miradasdoc.com http://miradasdoc.com/mdoc2018/documental-animacion-una-propuesta-lo-real-2/

Moore, S. (2011). Animating unique brain states. Animation Studies Online Journal, 6.

Nichols, B. (1994). Blurred boundaries: Questions of meaning in contemporary culture. Indiana University Press.

- (1997). La representación de la realidad: cuestiones y conceptos sobre el documental. Barcelona: Paidós.

- (2001). Documentary film and the modernist avant-garde. Critical Inquiry, 27(4), 580-610.

Poyato Sánchez, P. (2016). La dimensión política de los primeros documentales del Marqués de Villa-Alcázar. Zer 21(41), 209-226.

Quintana, À. (2003). Fábulas de lo visible. El cine como creador de realidades. Barcelona: Acantilado. - (2011). Después del cine. Imagen y realidad en la era digital. Barcelona: Acantilado. 
Ramonet, I. (1998). La tiranía de la comunicación. Barcelona: Debate.

Renov, M. (2004). The subject of documentary. Minneapolis: University of Minnesota Press.

Russell, C. (1999). Experimental Ethnography. The Work of Film in the Age of Video. Durham: Duke University Press.

Tagg, J. (2005). El peso de la representación: ensayos sobre fotografía e historias. Barcelona: Gustavo Gili.

VV.AA. (2015). Historietas X la identidad de Abuelas de la Plaza de mayo. http://hisxi.blogspot. $\mathrm{com} /$

Vigo, J. (1930). Vers un cinéma social. Reproducido en Vigo, J. (1985). Euvre de cinéma. Paris: La Cinémathèque française/L'herminier.

Virilio, P. (1988). Estética de la desaparición. Barcelona: Anagrama. 